\title{
ASSESSMENT OF THE CRITICAL SUCCESS FACTORS THAT ENABLE IMPLEMENTATION OF INDUSTRY 4.0 CONCEPTS IN MANUFACTURING COMPANIES WITHIN THE SME SECTOR IN THE CZECH REPUBLIC
}

\author{
Fortune NWAIWU(D) ${ }^{*}$, Meri DUDUCI $\mathbb{D}^{2}$, Felicita CHROMJAKOVA(D) \\ ${ }^{1}$ Department of Industrial Engineering, Faculty of Management and Economics, \\ Tomas Bata University, Mostni 5139, 76001, Zlin, Czech Republic \\ ${ }^{2}$ Department of Economics and Management, Faculty of Management and Economics, \\ Tomas Bata University, Mostni 5139, 76001, Zlin, Czech Republic
}

*E-mail: nwaiwu@utb.cz

\begin{abstract}
Purpose - the research analyses and identifies, factors that influence and have the most impact in achieving a sustainable process management model in the implementation of Industry 4.0 concepts within production based SMEs.

Research methodology - the research adopted qualitative and quantitative research. The qualitative approach involved an extensive and systematic review of literature while the quantitative approach involved the use of an online questionnaire used to collect data and analyzed using confirmatory factor analysis to test the measures of the constructs in the proposed conceptual framework.
\end{abstract}

Findings - the result from the research shows the main influencing factor that enables successful implementation of the Industry 4.0 process management model in SMEs.

Research limitations - the main research limitation is that the SMEs covered in the quantitative aspect of the research is located in the Czech Republic. It would be interesting to have similar studies conducted in other geographies for comparison purposes.

Practical implications - the findings from the study are useful to practitioners and industry stakeholders who intend to develop the right process management model reliant on Industry 4.0 within their SMEs.

Originality/Value - the originality/value is based on the combination of a quantitative alongside the qualitative approach in investigating the phenomenon covered in the study.

Keywords: industry 4.0, digital technologies, digital transformation, digitalization, process management model.

JEL Classification: M11, M15, O33.

Conference topic: Digitalization of Business Processes: Trends, Challenges, Solutions.

\section{Introduction}

Manufacturing companies in the Small and Medium Scale (SME) segment of the industry are confronted with challenges related to productivity improvements in the operations and manufacturing processes. These challenges often lead to budget and time overruns which in turn leads to lower productivity, a reduction in competitiveness and ultimately a loss of profitability. Particularly, SMEs are confronted with difficulties in transitioning from their current processes to those that are compliant with smart factory technologies because of the lack of manpower and investment in emerging technology trends, especially within the purview of Information and Communications Technologies (ICTs), which is in contrast to large companies that are substantially more advanced in the integration of their production plants in higher-level IT systems than most SME companies(Lee, Bagheri, \& Kao, 2015; Lee, Kao, \& Yang, 2014).

Improving the overall efficiency of SME manufacturing processes leads to narrowing the gap between SMEs and large multinational companies in terms of productivity (Lee et al., 2015). These improvements can be achieved by introducing more efficient processes that take advantage of advanced technological innovation such as offered collectively under a group of technologies that are now shaping the next industrial revolution called Industry 4.0 which is largely shaped by ICTs dominated technologies. The term 'Industry $4.0^{\prime}$ basically describes the current technological trends that are shaping the fourth industrial revolution. It is about the next stage in the organization and control of the entire value stream along the lifecycle of production technologies (Chromjakova, 2017). 

4.0 concepts in manufacturing companies within the SME sector in the Czech Republic

Despite the recent growing interest in digital technologies and the "smart factory" concept, still, there are only a few SMEs have been able to navigate through the complexities of successful Industry 4.0 solutions adoption. Some of the reasons for the noticeable large failure rates can be related to the lack of formalized processes, lack of ICT knowledge as well as low-cost commercial systems. Recent developments have made it imperative to have a clear understanding of how best to operationalize the adoption and implementation of Industry 4.0 concepts in a strategic way that translates to positive process improvement outcomes for manufacturing companies operating at the small and medium scale enterprise (SME) level. Hence, there is a need to analyze and identify factors that influence and have the most impact on achieving sustainable process management models in the implementation of Industry 4.0 concepts within production based SMEs.

This study aims to address the gap by identifying critical success factors required for successful implementation of Industry 4.0 concepts in manufacturing companies within the SME sector, with a view to analyze and identify the factors that influence with the most impact, the achievement of sustainable process management models in the implementation of Industry 4.0 concepts. This will be done by addressing the following research questions: what are the relevant factors that enable the implementation of an efficient process management model that enables SMEs to achieve a higher level of Industry 4.0 compliance within their operations and manufacturing processes? And, how do these factors rank in their level of importance in enabling the SMEs to achieve their Industry 4.0 process management model implementation? The research adopts a mixed method approve which involves both the qualitative and quantitative methodological approaches and contributes to the existing body of knowledge to Industry 4.0 process management implementation in SMEs.

\section{Literature review}

The concept of Industry 4.0 is driven by four clusters of disruptive technologies: the first cluster is anchored on data, computational power, and connectivity - low-power, wide-area networks are one example; analytics and intelligence from the second cluster; while human-machine interaction makes up the third, comprising, examples include, touch interfaces and augmented reality; finally, digital-to-physical conversion is the fourth cluster, and it covers the following - advanced robotics and 3D printing are two examples (Wee, Kelly, Cattel, \& Breunig, 2015).

These disruptive technologies have also led to the emergence of recurrent themes in regards to process management and other related practices that are well established in manufacturing industries. In relation to productivity improvements within the manufacturing processes of companies, Gilchrist (2016) argues that Industry 4.0 will bring about improvements in the industrial processes within manufacturing as a whole, through engineering, material usage, supply chains, and product lifecycle management. The table below provides a summary of the major definitions of Industry 4.0 that is found in academic literature.

Table 1. Definitions of Industry 4.0 (source: authors' compilation)

\begin{tabular}{|l|l|}
\hline \multicolumn{1}{|c|}{ Author(s) } & \multicolumn{1}{c|}{ Definition of Industry 4.0 } \\
\hline Lydon (2016) & $\begin{array}{l}\text { Industry 4.0 is holistic automation, business information, and manufacturing execution architecture to } \\
\text { improve industry with the integration of all aspects of production and commerce across company } \\
\text { boundaries for greater efficiency. }\end{array}$ \\
\hline Gilchrist (2016) & $\begin{array}{l}\text { Industry 4.0 requires the integration of cyber-physical systems (CPS) in manufacturing and logistics } \\
\text { while introducing the Internet of Things (IoT) and services in the manufacturing process. It deploys the } \\
\text { tools provided by the advancements in operational, communication, and information technology to in- } \\
\text { crease the levels of automation and digitization of production, in manufacturing and industrial pro- } \\
\text { cesses. }\end{array}$ \\
\hline Davies (2015) & $\begin{array}{l}\text { Industry 4.0 is a term applied to a group of rapid transformations in the design, manufacture, opera- } \\
\text { tion, and service of manufacturing systems and products. Industry 4.0 depends on a number of new in- } \\
\text { novative technological developments such as ICTs, CPSs, Network communications, Simulation, and } \\
\text { Big Data. }\end{array}$ \\
\hline $\begin{array}{l}\text { Sanders, } \\
\text { Elangeswaran, and } \\
\text { Wulfsberg (2016) }\end{array}$ & $\begin{array}{l}\text { Industry 4.0 is the fourth industrial revolution, applying the principles of cyber-physical systems } \\
\text { (CPS), internet and future-oriented technologies and smart systems with enhanced human-machine in- } \\
\text { teraction paradigms. }\end{array}$ \\
\hline (Wee et al., 2015) & $\begin{array}{l}\text { McKinsey defines Industry 4.0 as digitization of the manufacturing sector, with embedded sensors in } \\
\text { virtually all product components and manufacturing equipment, ubiquitous cyber-physical systems, } \\
\text { and analysis of all relevant data. }\end{array}$ \\
\hline $\begin{array}{l}\text { Wagner, Herrmann, } \\
\text { and Thiede (2017) }\end{array}$ & $\begin{array}{l}\text { Industry 4.0 can be defined as the industrial vision to enable "people and things to be connected Any- } \\
\text { time, Anyplace, with Anything and Anyone, ideally using Any path/network and Any service". }\end{array}$ \\
\hline $\begin{array}{l}\text { Pfohl, Yahsi, and } \\
\text { Kuznaz (2015) }\end{array}$ & $\begin{array}{l}\text { Industry 4.0 is the sum of all disruptive innovations derived and implemented in a value chain to ad- } \\
\text { dress the trends of digitalization, autonomisation, transparency, mobility, modularization, and net- } \\
\text { work-collaboration and socializing of products and processes. }\end{array}$ \\
\hline
\end{tabular}



4.0 concepts in manufacturing companies within the SME sector in the Czech Republic

A review of the definitions captured in Table 1 indicates that a key concept common to them is that of what is described as - Cyber-Physical Systems (CPS), which basically describes a group or collection of transformative technologies that manage interconnected systems between their physical assets and computational capabilities (Lee et al., 2015). The CPS connects all physical devices to the Internet, it incorporates five functions: computing, communications, precision control, coordination, and autonomy. Smart products and smart production are made possible through the integration of the virtual world and the physical world (Zhou, Liu, \& Zhou, 2016).

Results from a research conducted by Pfohl et al. (2015) analyzed a total of 49 technologies which they identified as relevant in shaping the fourth industrial revolution, they reduced them to a group that are most relevant which fall under the following seven categories: digitalization, autonomisation, transparency, mobility, modularization, networkcollaboration and socializing of products and processes. Another interesting perspective is that of Petrasch and Hentschke(2016) whose assessment of Industry 4.0 is done in terms of technological concepts classified under three broad categories: Embedded Systems (ES)/CPS (Cyber-Physical Systems), Internet/Cloud of Things (IoT/CoT), Service-Oriented Architecture (SOA)/Internet of Services (IoS)/Cloud Computing (CC).

The idea of categorization is relevant in simplifying the inquiry into the dynamics of Industry 4.0 and all related concepts such as Lean Manufacturing which is a methodology with the potential to improve productivity and decrease costs in manufacturing organizations (Sanders et al., 2016); Business Process Modelling (BPM) which describes behavioral aspects of a system and are usually on the formal requirements or early design level (Petrasch \& Hentschke, 2016); and Cyber-Physical Systems and how they interact with current practices such as Lean Manufacturing in improving efficiency of existing processes analysis and modeling systems.

The following observations were made from the literature reviewed so far: firstly, there is a general consensus on the body of technological innovations upon which the concept of Industry 4.0 is anchored; secondly, there seems to be an absence of a generally agreed conceptual/theoretical framework upon which a deeper understanding of the dynamics of evolution and maturity of Industry 4.0 can be understood, this gap in framework also manifests itself in a lack of a generalized definition of the concept of Industry 4.0, this is partly attributable that the concept itself is only a recent phenomenon even though many of the technological innovations upon which it is anchored are older and have been in practice in one form or another; thirdly, the body of literature on Industry 4.0 in the Czech Republic is scanty, which is an indication of the level of maturity and adoption of the phenomenon among Czech industries; fourthly, it is also observed that a vast majority of studies conducted on this subject tended to have a qualitative bias, this could also be attributed to the lack of a conceptual/theoretical framework which makes the application of quantitative methods and statistical analysis somewhat difficult at the current stage of development of the subject. Table 2 provides a summary of relevant literatures reviewed as part of the process of building up a scientific basis for the research, the works covered research with varying methodological approaches and focus areas all on industry 4.0 related activities.

\section{Review of relevant success factors}

Small and Medium-sized Enterprise (SMEs) are the driving force of many manufacturing economies. As the backbone of the manufacturing industry, SMEs' impact on the Fourth Industrial Revolution is significant, SMEs often encounter a variety of challenges and barriers than larger companies in their quest to adopt technologies that would make them upgrade their processes to be in line with the trends of Industry 4.0 (Mittal, Khan, Romero, \& Wuest, 2018).

From the results of the research conducted by Müller et al. (2018) on Industry 4.0 and its impact on German SMEs, they were able to demonstrated that Industry 4.0 impacts SMEs from three dimensions, namely high-grade digitisation of processes, smart manufacturing, and inter-company connectivity; second, Industry 4.0 affects the three business model elements of manufacturing SMEs - value creation, value capture, and value offer - by giving specific examples for business model innovation in each of the three elements; and finally, both the role as a user and/or provider of Industry 4.0 and whether a company is internally motivated and/or externally pressured towards implementation have an impact on which business model elements are innovated.

Also, the role of strategy in influencing the impact the outcomes of implementation of Industry 4.0 concepts towards achieving an efficient process management model was corroborated by the findings from the research conducted by Ganzarain \& Errasti (2016), they argued that that based on results from their research, there is a real need for guided support in developing a company-specific Industry 4.0 vision and specific project planning. In another study by Mittal et al. (2018), they investigated how organizational fit intersects with Industry 4.0 in SMEs, their findings revealed the following outcomes: the current standard starting (base level) of most maturity models appears to be disconnected from the real digitization and smart manufacturing maturity level of many SMEs; the transition from a non-existent lower level "level 0", to the current base level, requires significant effort including a mindset change; maturity models and readiness assessments can be associated with a Smart Manufacturing (SM) toolkit; and SMEs need to develop their own, unique SM or Industry 4.0 vision and roadmap.

Hence, based on evidence obtained from the literature review, several factors have been shown to have a significant influence on how they impact the outcomes of the implementation of the Industry 4.0 concepts with a view to achieving improved process management within a production based SMEs. Some of the major factors that have been identified in literature as being of strategic importance include: organisational strategy (Strategy); how the set of digital 


\begin{tabular}{|c|c|c|c|c|c|c|c|c|c|c|}
\hline 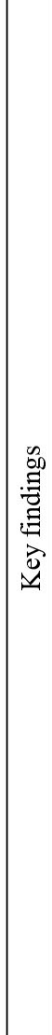 & 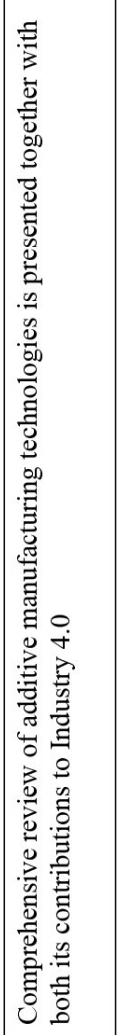 & 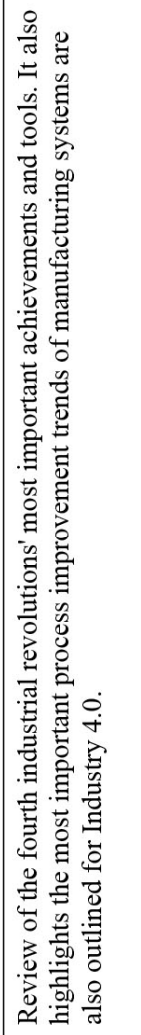 & 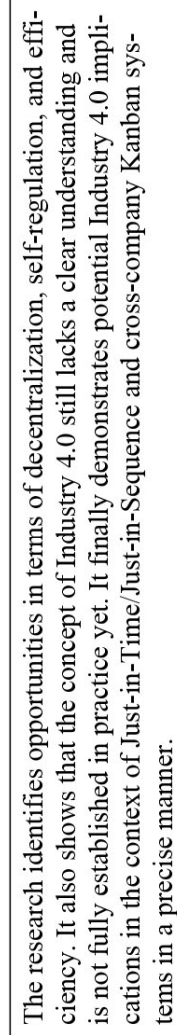 & 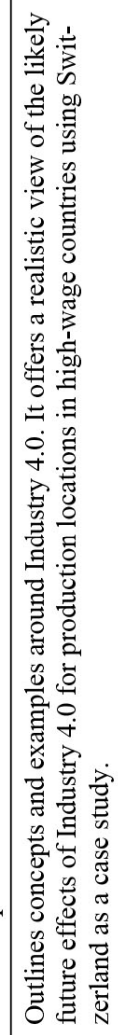 & 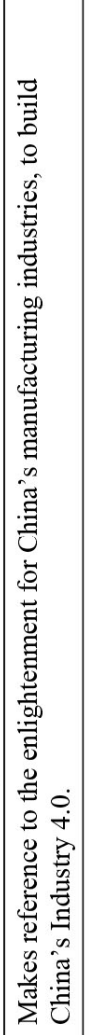 & 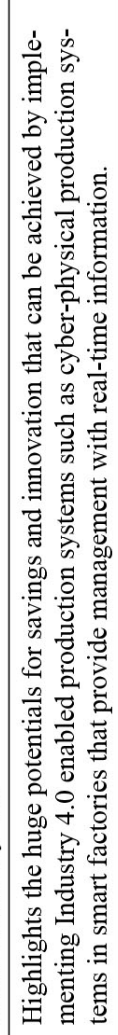 & 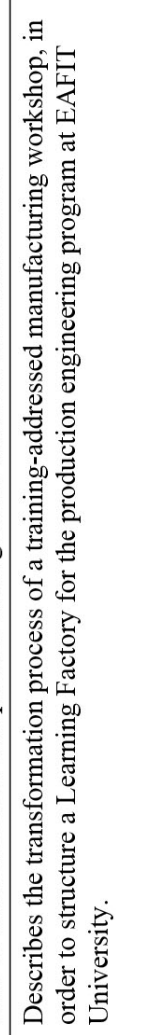 & 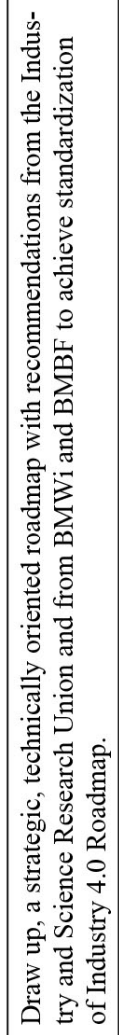 & 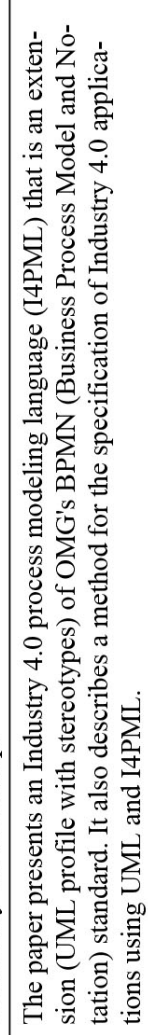 & 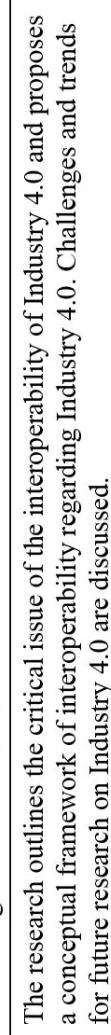 \\
\hline 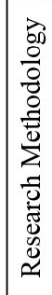 & 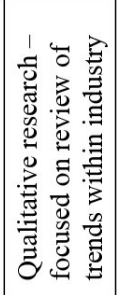 & 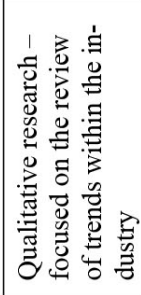 & 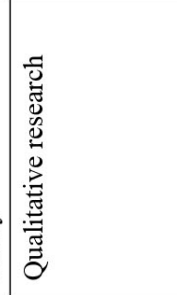 & 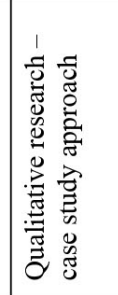 & 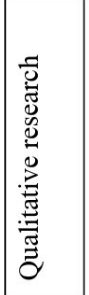 & 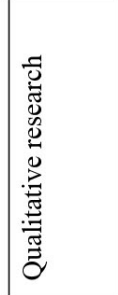 & 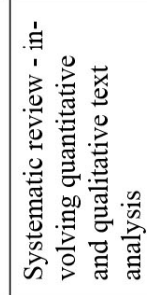 & 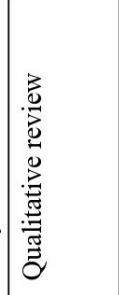 & 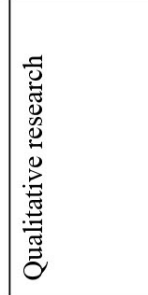 & 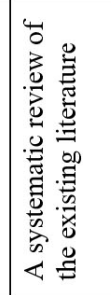 \\
\hline & 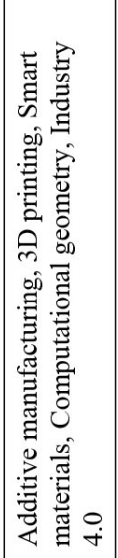 & 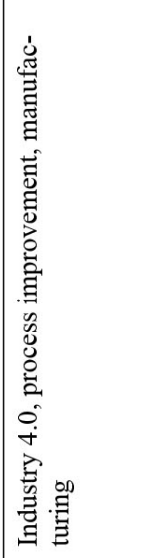 & 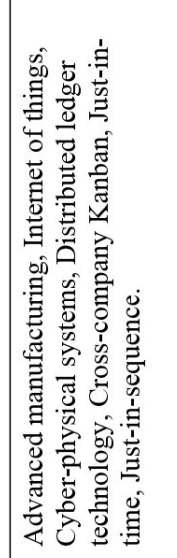 & 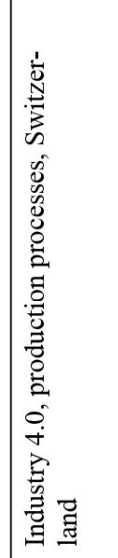 & 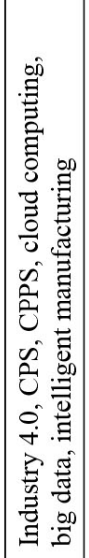 & 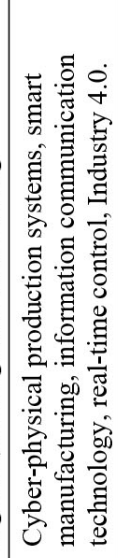 & 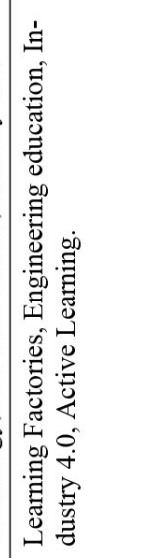 & 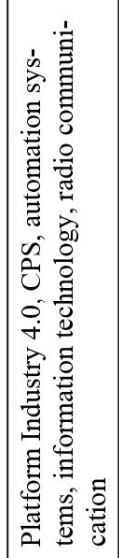 & 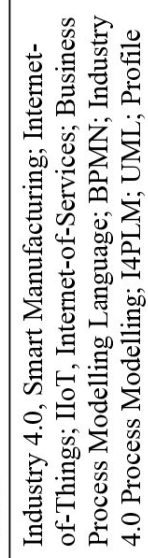 & 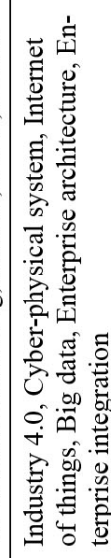 \\
\hline 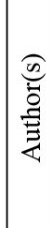 & 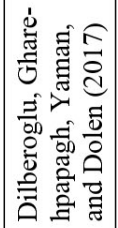 & 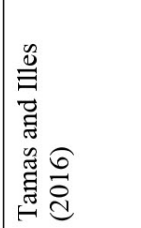 & 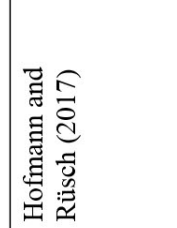 & 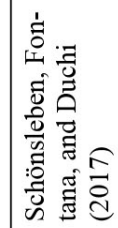 & 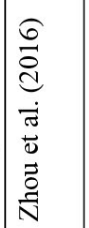 & 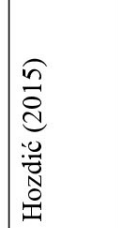 & 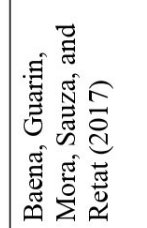 & $\begin{array}{l}0 \\
0 \\
0 \\
z \\
z \\
z \\
0\end{array}$ & 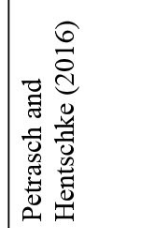 & \\
\hline
\end{tabular}




\begin{tabular}{|c|c|c|c|c|c|c|c|c|c|c|}
\hline 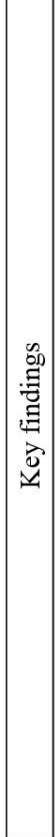 & 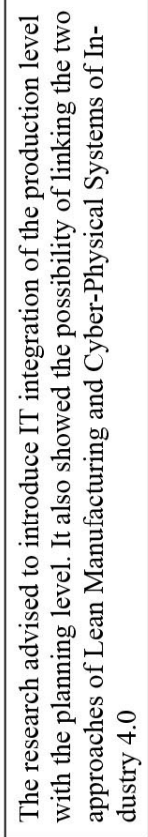 & 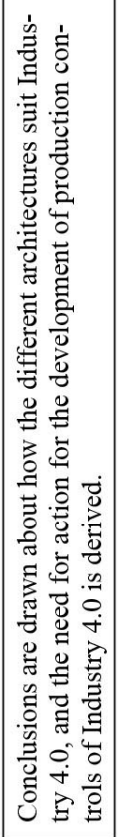 & 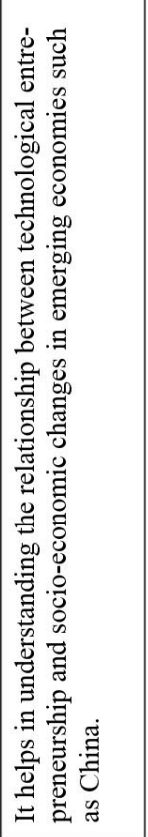 & 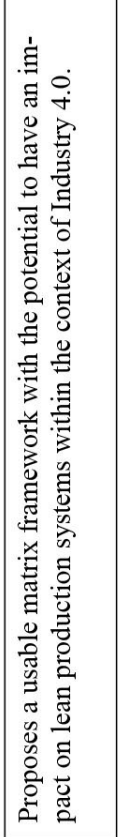 & 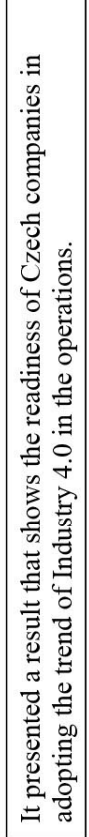 & 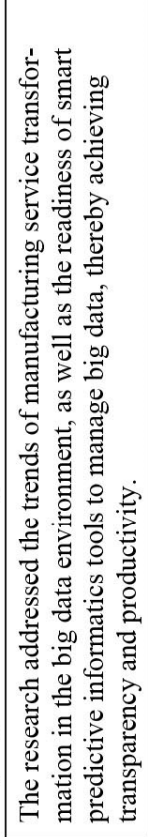 & 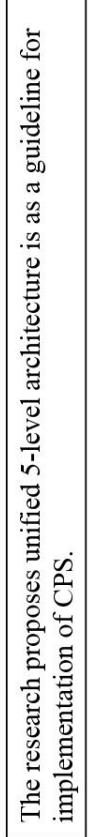 & 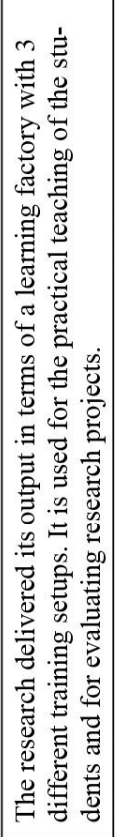 & 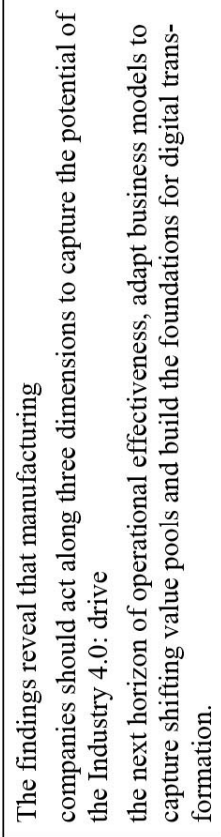 & 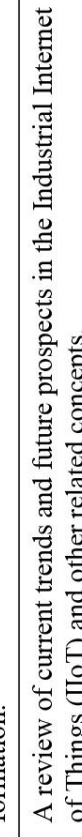 \\
\hline 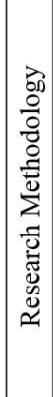 & 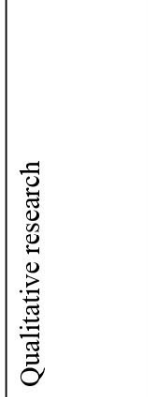 & 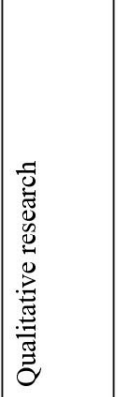 & 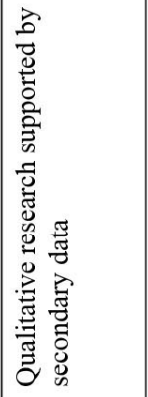 & 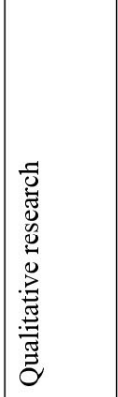 & 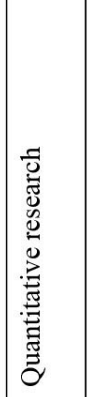 & 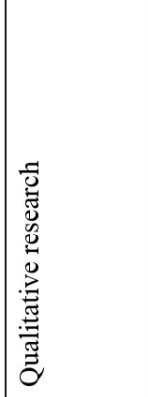 & 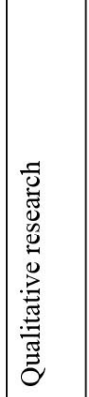 & 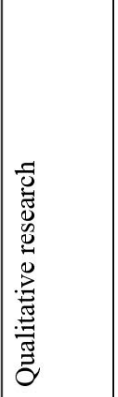 & 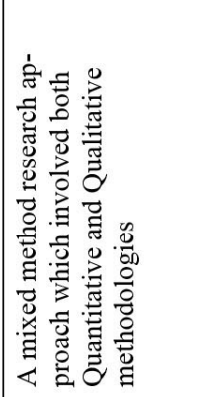 & 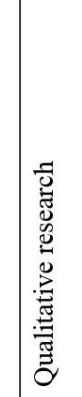 \\
\hline & 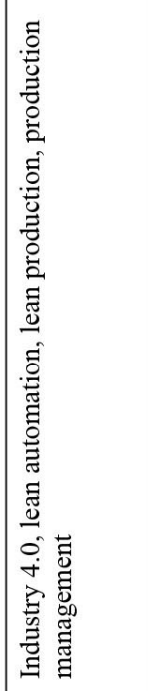 & 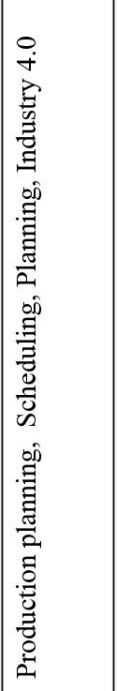 & 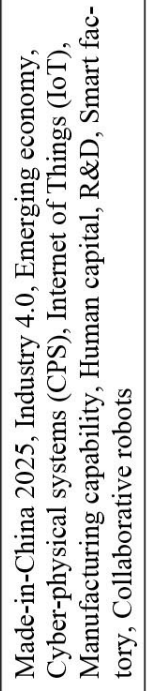 & 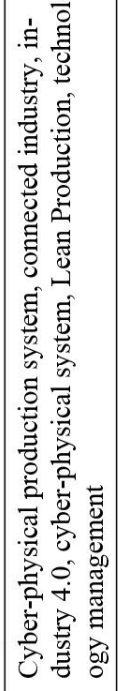 & 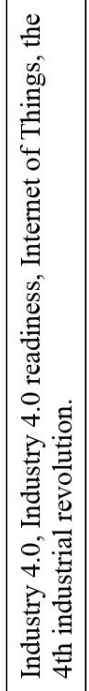 & 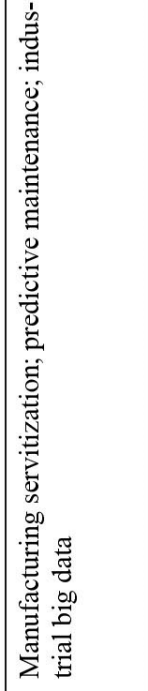 & 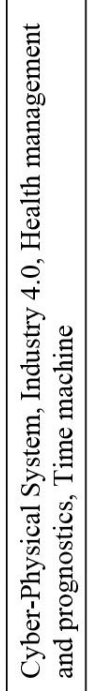 & 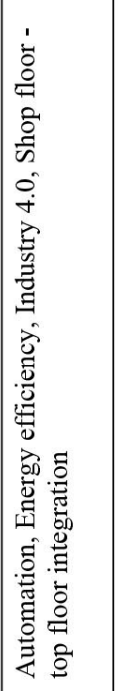 & 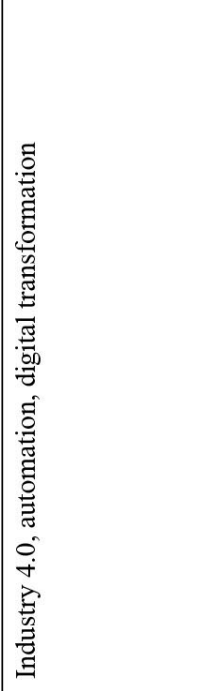 & 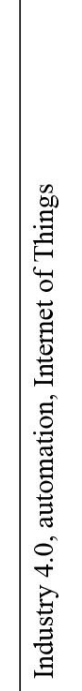 \\
\hline$E$ & 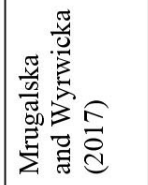 & 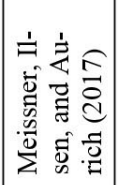 & & 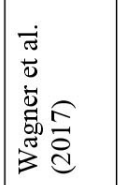 & 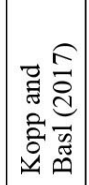 & 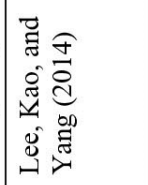 & 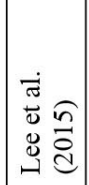 & 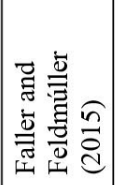 & 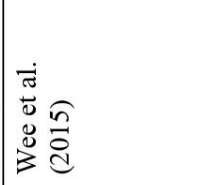 & 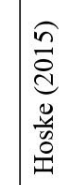 \\
\hline
\end{tabular}



4.0 concepts in manufacturing companies within the SME sector in the Czech Republic

technologies adopted and implemented fit into various organizational processes, business units or functions (Organisational fit); how these digital technologies translate to improved competitiveness for the company (Competitiveness); how these digital technologies directly impact on processes such as manufacturing, supply chain, logistics (Operations); and finally, the human resource availability and readiness within the company (Human resources), these set of factors are considered to be quite influential in determining overall outcomes (Chromjakova, 2017; Faller \& Feldmúller, 2015; Ganzarain \& Errasti, 2016; Müller et al., 2018; Rodič, 2017).

Based on the proposed conceptual framework (see Figure 1 below) that covers the following factors considered relevant to achieving the desired process management model for Industry 4.0 implementation in SMEs, the following hypotheses are advanced as a basis for quantitative investigation.

Strategy: various researchers have tried to relate the role of strategy in achieving sustainable growth and profitability for companies (Porter \& Kramer, 2007; Schumacher, Erol, \& Sihn, 2016; Wiersema \& Bantel, 1992). In relations to how strategy impacts on successful implementation of Industry 4.0 based process management model in SMEs, Fettig, Gačić, Köskal, Kühn, and Stuber (2018) argue that "implementing an Industry 4.0 process management strategy can lead to more autonomy, enrichment of functions, new and more flexible organizations that enable the development of individual skills and create opportunities for a better work-life balance." Therefore, to test the validity of this statement, a hypothesis is proposed as follows:

H1: Developing and implementing the right corporate and organizational strategy positively impacts the outcomes for achieving an optimal process management model for Industry 4.0 implementation in a company.

Competitiveness: Evidence from Research conducted by various authors have attempted to establish a connection between Industry 4.0 and the competitiveness of companies especially those involved in manufacturing based operations. They have argued that Industry 4.0 triggers changes in business models by affecting how these companies create value, capture value, and offer value to their customers and stakeholders, which in turn leads to improvements in their competitive position within their market segments, and ultimately enable them achieve sustainable growth and profitability(Faller \& Feldmúller, 2015; Müller et al., 2018). Hence, to test the relationship between the implementation of Industry 4.0 process management concepts and competitiveness of SMEs, a hypothesis is proposed as follows:

H2: The competitiveness of a company is positively correlated to its successful implementation of Industry 4.0 process management models.

Human Resources: The role of the human capital possessed by a company in helping it achieve its corporate and organizational goals, especially with respect to the company being able to successfully achieve digital transformation in its quest to implement Industry 4.0 process management models within its production based activities, has been extensively researched by various researchers both within business and the academic environments(Fettig et al., 2018; Shamim, Cang, Yu, \& Li, 2016; Sivathanu \& Pillai, 2018). Fettig et al. (2018) argues that "notes that IT-competencies of all industrial job descriptions will increase, and in combination with an overall process understanding are necessary factors of success". Hence, to test the relationship between the implementation of Industry 4.0 process management concepts and its human resources, a hypothesis is proposed as follows:

H3: The human resources possessed by a company have a positive influence on its ability to successfully implement Industry 4.0 process management models.

Operations: In general, Industry 4.0 particularly focuses on how digital technologies are adopted and implemented within operations focused processes of a company such as its manufacturing, supply chain and logistics related business processes. The need for adoption and implementation of these technologies is informed by a desire to achieve process optimization in ways that would enable improvements in processes, reduce wastages, reduce turnaround time, achieve lower cost efficiency and ultimately lead to improvements in returns on investments (RoI), thereby leading to sustainable long-term growth for the company (Ford, 2015; Müller et al., 2018; Oesterreich \& Teuteberg, 2016). Therefore, it is a widely held belief within the research community that successful implementation of the Industry 4.0 process management model within the operations segment of a company will ultimately lead to sustainable growth and profitability for the overall business. Hence, to test the relationship between the implementation of Industry 4.0 process management concepts within a company's operations business processes and its profitability, a hypothesis is proposed as follows:

H4: Adopting and implementing the appropriate digital technologies within the operations processes of a company leads to positive outcomes in a successful implementation of Industry 4.0 process management models.

Organizational Structure: Fettig et al. (2018) comment that organizational structure plays a critical role in supporting the successful implementation of Industry 4.0 concepts and principles in the processes of a business entity. Fettig et al. (2018) conceptualize the organizational structure to include - corporate strategy, work organization, and human resources. They argue that beyond technology, the process organization and structure are a key factor that contributes and determines the overall success of achieving process management improvements that lead to successful Industry 4.0 compliance for the organization. A corresponding hypothesis is proposed to test the validity of this claim as follows: 
H5: A well aligned organizational structure positively complements the adoption and implementation of the appropriate digital technologies for specific processes/business units, positively correlated to its successful implementation of Industry 4.0 process management models.
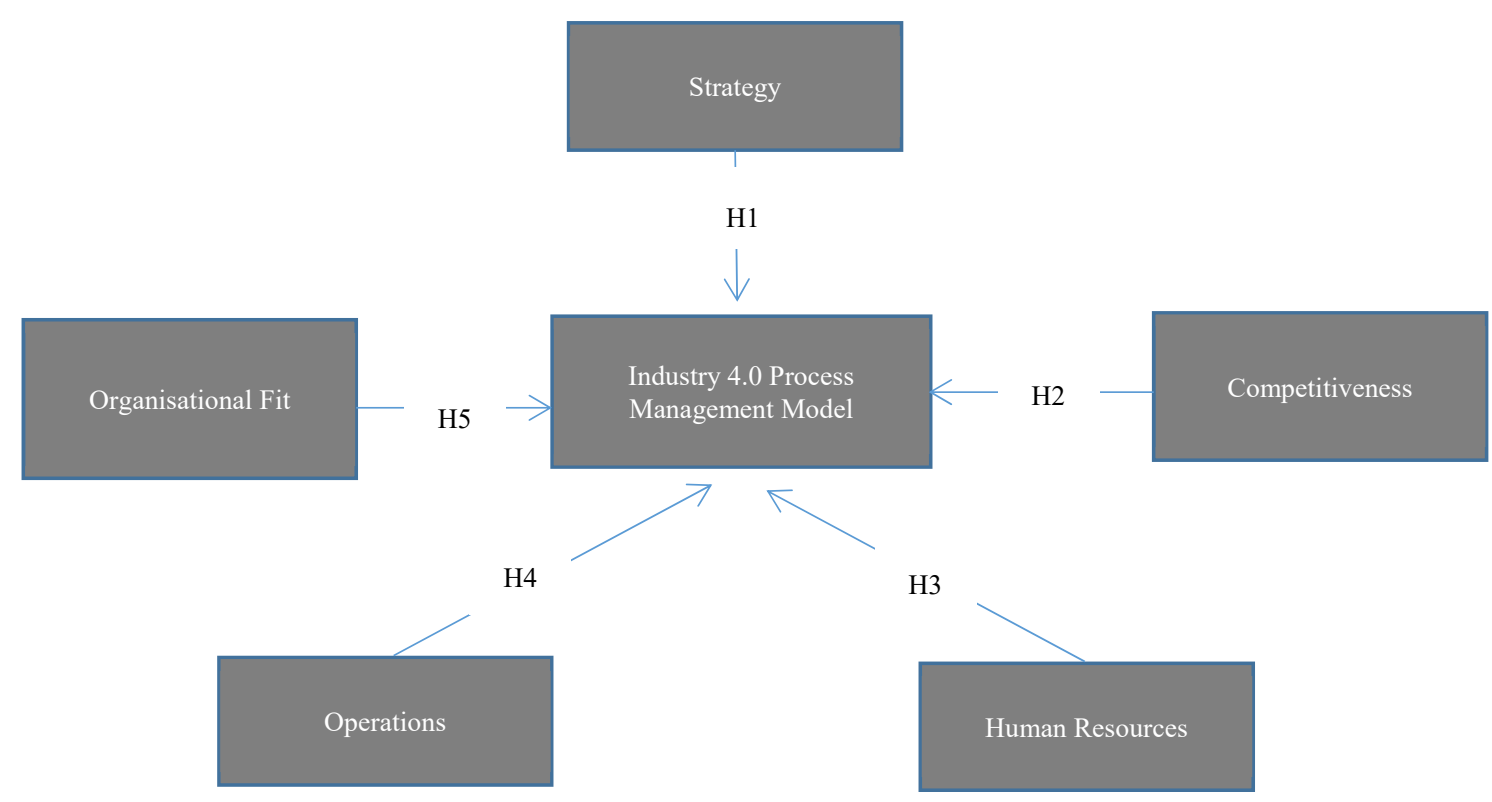

Figure 1. A proposed conceptual framework for Industry 4.0 Process Management Model (source: authors' proposed model)

\section{Methodology}

The research is conducted using a mixed methods approach that employs both qualitative and quantitative methodological approaches in providing answers to both research questions covered by the studies. The qualitative methodological approach involved an extensive and systematic review of relevant literature both within an industry and academia. This was necessary for providing answers to the first research question on the relevant factors that enable the implementation of efficient Industry 4.0 process management model in SMEs. Academic sources used in the literature review included research articles from journals indexed in reputable scientific databases such as Scopus, Web of Science and ERIH PLUS, while business sources relied on publications by renowned experts and consulting firms such as PwC, KPMG, Accenture, etc. The literature search result yielded a substantial amount of articles which included the keywords employed in the search, the basic keywords used in the search were - Industry 4.0, SMEs, digital transformation, process management models. The keywords were combined in various search inputs that led to various data outputs. Pre- and post-qualification criteria were used in filtering the results of the literature search output to narrow it down to literature that specifically meets the criteria to be included in the study. The findings of the systematic literature review were instrumental in developing the proposed conceptual framework

For the quantitative aspect of the research, data were collected over a three-month period using an online questionnaire developed using the Google forms app on the Google platform, and distributed among SMEs based within the Czech Republic. Questionnaire distribution was carried out in a way that ensured that the target respondents were selected from a pool of management cadre personnel in selected business enterprises that fall within the SME bracket and also involved in manufacturing; supply chain and logistics based operations. A total of 209 respondents completed the survey over a three-month period. The questionnaire was developed both in the English and Czech languages to ensure that language was not a barrier to the targeted respondents irrespective of their language capabilities and proficiency. A confirmatory factor analysis - CFA (Harrington, 2008; Wood, 2008) was used to test if the measures of a construct in the proposed conceptual framework were consistent with the understanding of the nature of the constructs. The quantitative aspect of the analysis was useful in providing a response to the second research question on how to do the constructs in the proposed conceptual framework rank in their level of importance in enabling the SMEs to achieve their Industry 4.0 process management model implementation

\section{Results and discussions}

The quantitative aspect of this research was useful in the analysis of the second research question of how the hypothesis connected to the factors impacts on how the implementation of Industry 4.0 is influenced by the process management model implementation. A total of five hypotheses were analyzed according to the data gathered through the questionnaire. These hypotheses are ranked according to their level of importance. 

4.0 concepts in manufacturing companies within the SME sector in the Czech Republic

The questionnaire was administered to the respondents through the use of an electronic form created on the Google online documents platform, this was necessary in order to gather a higher number of responses that are geographically dispersed to businesses in such a way that not restricted to particular nationalities, with respondents being of different business levels within their respective organizations, a deliberate effort was made to ensure that the respondents' business level or position within their organizations was of management cadre and higher. The respondents were required to provide answers to questions presented to them through the use online questionnaire on a scale between 1 (the weakest) to 5 (strongest), the data gathered through the questionnaire was analyzed through the Confirmatory Factor Analysis (CFA). The CFA enables the researchers to analyze the relationship between the variables of the proposed conceptual framework based on the underlying definition of the questionnaire.

The results from the CFA (see Figure 2 below) showed the most important factor that determined the result of the questionnaire. The following factors were analyzed in the statistical program: Strategy (stra), Competitiveness (comp), Human Resources (hr), Operations (opera), Organisational Fit (orgfit) and Industry 4.0 Process Management Model (pmm). The data analysis based on the CFA shows the statistical weight that these factors have based on the questions as contained in the questionnaire administered to the respondents.

Upon conclusion of the statistical analysis, the results enabled the researchers to identify the hypothesis and factor that have a higher weight towards the correct implementation of the industry 4.0 process management model. According to the results from the statistical program, the weights towards the PMM (process Management Model) is not divided in a way that results in the creation of a big difference between the most important factor and the less important factors. From all the factors/constructs analyzed, only one factor/construct meets the criteria, and it is the Human Resources factor/construct. This is also consistent with the observed evidence obtained from the extensive review of business and scientific literature on the subject matter, where it has been established by other researchers that the human resources components of organizations play a vital role in their ability to successfully implement industry 4.0 based process management models that rely on digital technologies for successful transformation and improvements of manufacturing, logistics and supply chain related organizational processes/activities within the companies. Hence, the right training and organization of Human Resources play a very important role in the successful implementation of the new wave of Industry 4.0. The ranking below shows the hypothesis and factors according to their level of importance, from most important (HR) to least important (stra): H3: Human Resources (HR); H4. Operations (opera); H5. Organizational Fit (orgfit); H2. Competitiveness (comp); H1. Strategy (stra).

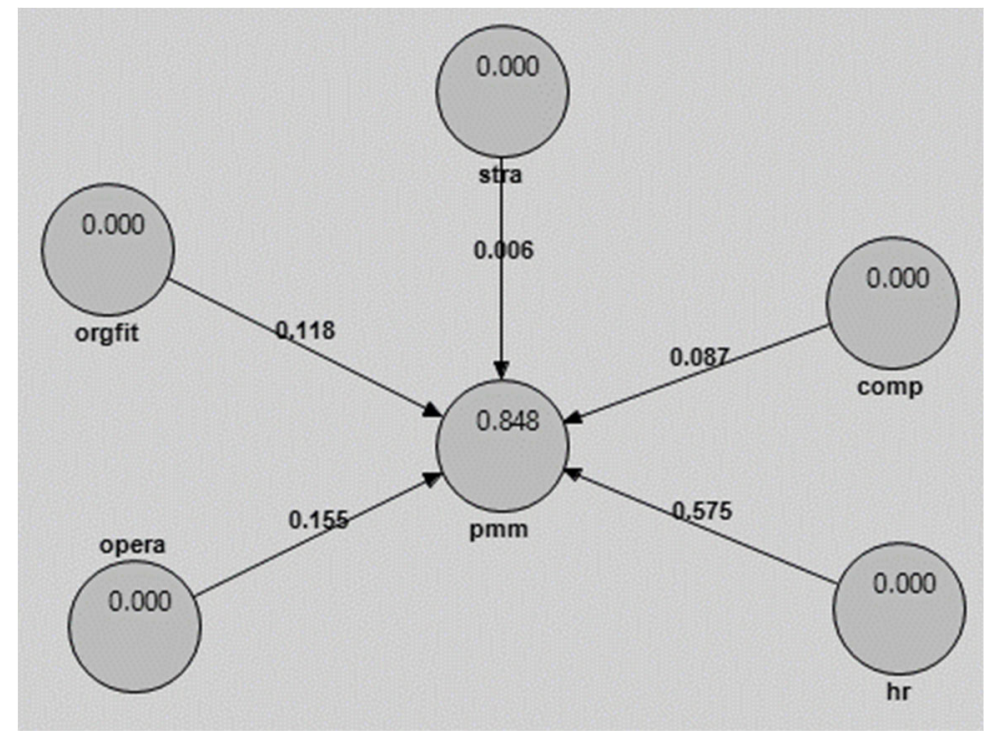

Figure 2. Result of statistical analysis of the proposed conceptual framework on Industry 4.0 Process Management Model (source: authors' data analysis result)

From figures contained in Table 3 for quality criteria, it is possible to check in more detail the result output of the PLS statistical program. The Composite Reliability results of all the factors show a good scale of reliability and internal consistency of the data for each factor. The Goodness of fit R-square has shown that only the Process Management Model is a valid factor that explains the dependency of this hypothesis towards each other. This is another confirmation of the previous results from the figure below that shows how the majority of this process is highly connected with the management model and less with the other factors taken into consideration. 
Nwaiwu, F.; Duduci, M.; Chromjakova, F. 2019. Assessment of the critical success factors that enable implementation of industry 4.0 concepts in manufacturing companies within the SME sector in the Czech Republic

Table 3. Quality criteria (source: authors' data analysis result)

\begin{tabular}{|c|c|c|c|c|c|c|}
\hline & AVE & Composite Reliability & R Square & Cronbach`s Alpha & Communality & Redundancy \\
\hline Comp & 0.9152 & 0.9774 & 0 & 0.9691 & 0.9152 & 0 \\
\hline Hr & 0.9096 & 0.9757 & 0 & 0.9668 & 0.9096 & 0 \\
\hline Opera & 0.8908 & 0.989 & 0 & 0.9877 & 0.8908 & 0 \\
\hline Orgfit & 0.886 & 0.9749 & 0 & 0.9678 & 0.886 & 0 \\
\hline Pmm & 0.954 & 0.9842 & 0.8477 & 0.9759 & 0.954 & 0.1378 \\
\hline Stra & 0.9043 & 0.9742 & 0 & 0.9647 & 0.9043 & 0 \\
\hline
\end{tabular}

Table 4. Total effect (source: authors' data analysis result)

\begin{tabular}{|c|c|c|c|c|c|}
\hline & Original Sample & Sample Mean & Standard Deviation & Standard Error & T Statistics \\
\hline comp -> pmm & 0.0869 & 0.0584 & 0.175 & 0.175 & 0.4967 \\
\hline $\mathrm{hr}->$ pmm & 0.5749 & 0.5627 & 0.1305 & 0.1305 & 4.4056 \\
\hline opera -> pmm & 0.1551 & 0.18 & 0.1955 & 0.1955 & 0.7932 \\
\hline orgfit -> pmm & 0.1183 & 0.116 & 0.1459 & 0.1459 & 0.8109 \\
\hline stra -> pmm & 0.0058 & 0.022 & 0.1288 & 0.1288 & 0.0447 \\
\hline
\end{tabular}

In the data given by Cronbach's Alpha, it is evident that the factors have an internal consistency with one another. The results from it show that the questions have a high connection and reliability between them as the results are quite good and very similar. Regarding the results of Communality, it is very important to be higher than 0.5 as it shows the importance of the factors towards the general result of the questionnaire. All the commonalities of the 6 variables are higher than 0.5, which shows us that there is no problem in relation to this test. For the Redundancy test, it is once again proved as in the R Square test that only the Process Management Model is a significant factor the others have shown the result of 0 validity.

From Table 4 for total effect, the results show in a generalized way the relationship of the 5 factors taken into the study with the process management model conceptual framework. Once again, this test shows that the most relevant factor in relation to PMM is Human resources. With a low standard error and a normal T Statistics, it confirms the result that the original sample and the sample mean to have no big differences between them. The other combinations clearly demonstrate the fact that there is not a high correlation and not a high dependency between the other variables to the Process Management Model. The lowest combinations are the Competitiveness and Strategy factor as the less correlated factors in this factor analysis.

\section{Conclusions}

In this paper, an analysis of the new industrial revolution named Industry 4.0 was conducted. This new wave of industry and the new way of doing business is analyzed from the point of view of Small and Medium Enterprises. There are significant differences in how SMEs implement new processes especially those reliant on digital technologies when compared to larger companies. Due to the fact that Industry 4.0 requires a high number of business processes to be changed and replaced by new ones this causes the SMEs to face different challenges while implementing this new system such as manpower; investments in emerging technologies related to ICTs and IT systems. As the literature review shows there are different research being conducted in order to make this implementation an easy and most important a successful process, still few SMEs have fully implemented 4.0. This is why during this research there have been pointed out several successful factors that enable the implementation of the efficient process management model.

Through two different analyses, qualitative and quantitative in this research, we analyzed the main factors that if implemented and correctly managed can lead to a successful implementation of the management model of industry 4.0. Based on evidence from the literature review, it is possible to point out the main influencing factors that highly affect the correct implementation. The study of Mittal et al. (Mittal et al., 2018) gives a clear understanding of this paper on how the organizational fit affects the challenges faced by the SMEs. Also there are other factors that are considered to be highly connected and deeply affecting the level of difficulty implementation; the importance of the competitiveness in the market in order to offer the latest technology (Competitiveness); the impact that the new technologies have towards the different process of manufacturing logistic and supply chain (Operations); human resources level of preparation and readiness (Human Resource); the new organization strategies adopted from the companies in order to have a faster and easier implementation of 4.0 (Strategy) and Organizational Fit (Chromjakova, 2017; Faller \& Feldmuller, 2015; Ganzarain \& Errasti, 2016; Muller et al., 2017). From the literature review research, it was shown that all the five factors have an impact on the process management model implementation, due to different levels of importance that they show toward it. 

4.0 concepts in manufacturing companies within the SME sector in the Czech Republic

According to these conclusions gathered from the qualitative research of this paper, it was then continued with the quantitative research where the creation of a questionnaire gave a clear understanding of what the importance of these factors is toward the process management model. The fact of the questionnaire being distributed in different countries and different levels of SMEs give an adequate result of the important factors that are highly correlated with the process management model of implementing industry 4.0. After all the results were gathered then a Confirmatory Factor analysis where all the data collected through a statistical program were possible to be analyzed according to the factors gathered in the qualitative research. According to the results, it is observed the high dependency and importance of Human Resources towards the Process Management Model. In different tests, it is perceived that the factor of PMM (process management model) is of high importance and relevance as it follows all the rules of the statistical tests.

Differently, from the literature review result from the quantitative research, it was shown that not all factors have a high impact on the process management model, but only Hypothesis number 3 shows a high weight into the correct implementation. This different result is due to the data gathered and it can be explained because of the different levels of industry 4.0 from the respondents. Also, the different countries where the answers were gathered from effect at a high level the different results.

Through both kinds of research, it is possible to understand that with a correct model of implementation (PMM) it is possible to have a successful and quicker implementation of the new industrial revolution. The correct combination of Human Resources with Process Management Model in implementing the Industry 4.0 shows the high importance that the correct training and readiness of the HR plays a significant role into an easier and most importantly successful change towards the new wave of industry. Changes are always difficult to be applied especially when it exists a high gap between SMEs and big enterprises, but when a company requires to maintain their role and improve even higher in the market have to embrace the change and have to follow the big revolution towards the innovation. To conclude this paper, it is important to state that our aim was to identify a specific path that should be carefully analyzed from the SMEs and taken very much into consideration in order to have an easier adaptation into the Industry 4.0.

\section{Acknowledgements}

Fortune Nwaiwu: theoretical research for the basis of a conceptual framework, developed a questionnaire and collected data. Meri Duduci: data analysis and interpretation of results. Felicita Chromjakova (Prof.): supervisory role and secured funding for research from grant awarding agency.

\section{Funding}

The research is supported by funding provided for IGA/FaME/2018/005 - Process management model proposal for implementation of Industry 4.0 in SMEs.

\section{Disclosure statement}

This research paper does not have any competing financial, professional or personal interests from other parties.

\section{References}

Baena, F., Guarin, A., Mora, J., Sauza, J., \& Retat, S. (2017). Learning Factory: The Path to Industry 4.0. Procedia Manufacturing, 9, 73-80. https://doi.org/10.1016/j.promfg.2017.04.022

Chromjakova, F. (2017). Process stabilization-key assumption for implementation of Industry 4.0 concept in industrial company. Journal of systems integration, 8(1), 3-12. https://doi.org/10.20470/jsi.v8i1.295

Davies, R. (2015). Industry 4.0. Digitalisation for productivity and growth. European Parliamentary Research Service, (September), 10.

Dilberoglu, U. M., Gharehpapagh, B., Yaman, U., \& Dolen, M. (2017). The Role of Additive Manufacturing in the Era of Industry 4.0. Procedia Manufacturing, 11, 545-554. https://doi.org/10.1016/j.promfg.2017.07.148

DIN. (2016). German Standardization Roadmap: Industry 4.0. German Standarization Roadmap Industry 4.0 Version 2, 77.

Faller, C., \& Feldmúller, D. (2015). Industry 4.0 learning factory for regional SMEs. Procedia CIRP, 32, 88-91. https://doi.org/10.1016/j.procir.2015.02.117

Fettig, K., Gačić, T., Köskal, A., Kühn, A., \& Stuber, F. (2018). Impact of Industry 4.0 on Organizational Structures. In 2018 IEEE International Conference on Engineering, Technology and Innovation (ICE/ITMC) (pp. 1-8). https://doi.org/10.1109/ICE.2018.8436284

Ford, M. (2015). Industry 4.0: Who Benefits? SMT: Surface Mount Technology, 30(7), 52-55.

Ganzarain, J., \& Errasti, N. (2016). Three Stage Maturity Model in SME's towards Industry 4.0. Journal of Industrial Engineering and Management, 9(5), 1119-1128. https://doi.org/10.3926/jiem.2073

Gilchrist, A. (2016). Introducing Industry 4.0. In A. Gilchrist (Eds.), Industry 4.0 (pp. 195-215). Apress, Berkeley, CA. https://doi.org/10.1007/978-1-4842-2047-4_13

Harrington, D. (2008). Use of Confirmatory Factor Analysis with Multiple Groups. In D. Harrington (Eds.), Confirmatory Factor Analysis. Oxford: Oxford University Press. https://doi.org/10.1093/acprof:oso/9780195339888.003.0005 
Nwaiwu, F.; Duduci, M.; Chromjakova, F. 2019. Assessment of the critical success factors that enable implementation of industry 4.0 concepts in manufacturing companies within the SME sector in the Czech Republic

Hofmann, E., \& Rüsch, M. (2017). Industry 4.0 and the current status as well as future prospects on logistics. Computers in Industry, 89, 23-34. https://doi.org/10.1016/j.compind.2017.04.002

Hoske, M. T. (2015). Industrial internet of things, industry 4.0. Control Engineering, 62(6), 26-35. https://doi.org/10.1007/978-14842-2047-4

Hozdić, E. (2015). Smart factory for industry 4.0: A review. International Journal of Modern Manufacturing Technologies, 7(1), 28-35. https://doi.org/10.1016/j.procir.2016.03.162

Kopp, J., \& Basl, J. (2017). Study of the Readiness of Czech Companies to the Industry 4.0. Journal of systems integration, 8(3), 40-45. https://doi.org/10.20470/jsi.v8i2.313

Lee, J., Bagheri, B., \& Kao, H. A. (2015). A Cyber-Physical Systems architecture for Industry 4.0-based manufacturing systems. Manufacturing Letters, 3, 18-23. https://doi.org/10.1016/j.mfglet.2014.12.001

Lee, J., Kao, H. A., \& Yang, S. (2014). Service innovation and smart analytics for Industry 4.0 and big data environment. Procedia CIRP, 1(16), 3-8. https://doi.org/10.1016/j.procir.2014.02.001

Li, L. (2017). China's manufacturing locus in 2025: With a comparison of "Made-in-China 2025" and "Industry 4.0". Technological Forecasting and Social Change, 135, 66-74. https://doi.org/10.1016/j.techfore.2017.05.028

Lu, Y. (2017). Industry 4.0: A survey on technologies, applications and open research issues. Journal of Industrial Information Integration, 6, 1-10. https://doi.org/10.1016/j.jii.2017.04.005

Lydon, B. (2016). Industry 4.0: Intelligent and flexible production. InTech Magazine, 63(5-6).

Meissner, H., Ilsen, R., \& Aurich, J. C. (2017). ScienceDirect Analysis of control architectures in the context of Industry 4.0. Procedia CIRP, 62, 165-169. https://doi.org/10.1016/j.procir.2016.06.113

Mittal, S., Khan, M. A., Romero, D., \& Wuest, T. (2018). A critical review of smart manufacturing \&amp; Industry 4.0 maturity models: Implications for small and medium-sized enterprises (SMEs). Journal of Manufacturing Systems, 49, 194-214. https://doi.org/10.1016/j.jmsy.2018.10.005

Mrugalska, B., \& Wyrwicka, M. K. (2017). Towards lean production in industry 4.0. Procedia Engineering, 182, $466-473$. https://doi.org/10.1016/j.proeng.2017.03.135

Müller, J. M., Buliga, O., \& Voigt, K.-I. (2018). Fortune favors the prepared: How SMEs approach business model innovations in Industry 4.0. Technological Forecasting and Social Change, 132, 2-17. https://doi.org/10.1016/j.techfore.2017.12.019

Oesterreich, T. D., \& Teuteberg, F. (2016). Understanding the implications of digitisation and automation in the context of Industry 4.0: A triangulation approach and elements of a research agenda for the construction industry. Computers in Industry, 83, 121139. https://doi.org/10.1016/j.compind.2016.09.006

Petrasch, R., \& Hentschke, R. (2016). Process modeling for industry 4.0 applications: Towards an industry 4.0 process modeling language and method. In 2016 13th International Joint Conference on Computer Science and Software Engineering, JCSSE 2016. https://doi.org/10.1109/JCSSE.2016.7748885

Pfohl, H.-C., Yahsi, B., \& Kuznaz, T. (2015). The impact of Industry 4.0 on the Supply Chain. Proceedings of the Hamburg International Conference of Logistic (HICL), 20, 32-58. https://doi.org/10.13140/RG.2.1.4906.2484

Porter, M. E., \& Kramer, M. R. (2007). Strategy \& society: The link between competitive advantage and corporate social responsibility. Harvard Business Review, 84(12), 78-92. https://doi.org/10.1108/sd.2007.05623ead.006

Rodič, B. (2017). Industry 4.0 and the New Simulation Modelling Paradigm. Organizacija, 50(3), $193-207$. https://doi.org/10.1515/orga-2017-0017

Sanders, A., Elangeswaran, C., \& Wulfsberg, J. (2016). Industry 4.0 implies lean manufacturing: Research activities in industry 4.0 function as enablers for lean manufacturing. Journal of Industrial Engineering and Management, 9(3), 811-833. https://doi.org/10.3926/jiem.1940

Schönsleben, P., Fontana, F., \& Duchi, A. (2017). What benefits do initiatives such as Industry 4.0 offer for production locations in high-wage countries? Procedia CIRP, 63, 179-183. https://doi.org/10.1016/j.procir.2017.03.356

Schumacher, A., Erol, S., \& Sihn, W. (2016). A maturity model for assessing Industry 4.0 readiness and maturity of manufacturing enterprises. Procedia CIRP, 52, 161-166. https://doi.org/10.1016/j.procir.2016.07.040

Shamim, S., Cang, S., Yu, H., \& Li, Y. (2016). Management approaches for Industry 4.0: A human resource management perspective. 2016 IEEE Congress on Evolutionary Computation, CEC 2016, 5309-5316. https://doi.org/10.1109/CEC.2016.7748365

Sivathanu, B., \& Pillai, R. (2018). Smart HR 4.0 - how industry 4.0 is disrupting HR. Human Resource Management International Digest, 26(4), 7-11. https://doi.org/10.1108/HRMID-04-2018-0059

Tamas, P., \& Illes, B. (2016). Process Improvement trends for manufacturing systems in Industry 4.0. Academic Journal of Manufacturing Engineering, 14(4), 119-125.

Wagner, T., Herrmann, C., \& Thiede, S. (2017). Industry 4.0 Impacts on Lean Production Systems. Procedia CIRP, 63, $125-131$. https://doi.org/10.1016/j.procir.2017.02.041

Wee, D., Kelly, R., Cattel, J., \& Breunig, M. (2015). Industry 4.0 - how to navigate digitization of the manufacturing sector. McKinsey \& Company Report, 1-62. https://doi.org/10.1007/s13398-014-0173-7.2

Wiersema, M. F., \& Bantel, K. A. (1992). Top management team demography and corporate strategic change. Academy of Management Journal, 35(1), 91-121. https://doi.org/10.5465/256474

Wood, P. (2008). Confirmatory factor analysis for applied research. The American Statistician, 62(1), 91-92. https://doi.org/10.1198/tas.2008.s98

Zhou, K., Liu, T., \& Zhou, L. (2016). Industry 4.0: Towards future industrial opportunities and challenges. In 2015 12th International Conference on Fuzzy Systems and Knowledge Discovery, FSKD 2015 (pp. 2147-2152). https://doi.org/10.1109/FSKD.2015.7382284 